\title{
Knowledge, attitude and practice of contraception complications among hospitalized women following self-induced medical abortion at tertiary hospital
}

\author{
Aparajita Pal, Jahar Lal Baidya*
}

Department of Obstetrics and Gynecology, Agartala Government Medical College, Agartala, Tripura, India

\author{
Received: 31 March 2020 \\ Revised: 05 May 2020 \\ Accepted: 11 May 2020 \\ *Correspondence: \\ Dr. Jahar Lal Baidya, \\ E-mail: iamjlbaidya@hotmail.com
}

Copyright: () the author(s), publisher and licensee Medip Academy. This is an open-access article distributed under the terms of the Creative Commons Attribution Non-Commercial License, which permits unrestricted non-commercial use, distribution, and reproduction in any medium, provided the original work is properly cited.

\begin{abstract}
Background: Unwanted pregnancies in women and complications of induced abortions are an important health problem in the world. There is recent trend of self-induced medical abortion pill use over the counter without knowing the recommendations. Objectives of this study were to study socio demographic profile, presentations, management of hospitalized women for medical abortion related complications. To explore out contraceptive practices in those women. To way out the reasons for choosing medical abortion by women.

Methods: Women of reproductive age group (15-45 years) who admitted in department of Obstetrics and Gynaecology Medical College with the complications following self-induced medical abortion were enrolled. Patients' demographic profile, socio-economic status, obstetric profile, KAP of contraception, logical reasons for selfinduced abortion were studied. Management of each case was done according to hospital protocols.

Results: The total number of patients that were enrolled for the study period was $100.37 \%$ of hospitalized women were between $18-25$ years age group and $45 \%$ of them had marriage at early age (15-20 years) and $46 \%$ were belonged to lower middle-class group. Majority of women with single living child with their last child <1-year age had taken abortion pills for unplanned pregnancy (49\%). $74 \%$ women had taken abortion pills over the counter for the first time and $88 \%$ women did have idea about contraception but never used. $70 \%$ of the women had to undergo surgical evacuation and six of them had undergone emergency laparotomy for ruptured tubal ectopic pregnancy. Post abortion counselling successfully convinced to accept combined oral contraceptive (31\%), followed by IUCD and permanent sterilization and $16 \%$ of women by medical abortion pill refused to accept contraception.

Conclusions: Pregnancy termination should be done by qualified medical personal with accurate information about safe medical abortion. Counselling of each couple is must to enhance continuous and consistent use of family planning methods.
\end{abstract}

Keywords: Attitude and practice of contraception, Knowledge, Family planning, Post abortion care and counselling, Safe abortion practices

\section{INTRODUCTION}

The most important right of women is the right to life and this is the supreme human right from which no derogation is permitted. But there are some controversial issues related for the supreme right and one such issue is question of right to abortion. India was the first country in the world to adopt an official population policy and launch official family planning program way back in 1952 and due importance to it is given by subsequent five year policies. ${ }^{1}$ Contraception in India is practiced primarily for birth limitation rather that for birth planning and it has been a single most important intervention to reduce burden of unwanted pregnancy. It has not 
eliminated the need for safe abortion because every method of contraception has an intrinsic failure rate even if used strictly as prescribed. In India morbidity and mortality rates due to pregnancy and its related complications are very high. To reduce maternal morbidity and mortality associated with illegal abortion the medical termination of pregnancy has been legalized in India when Government of India passed the Medical termination of pregnancy act in $1971 .^{2}$ But majority of women still turn to uncertified service provides or go for self-induced abortion. Unfortunately, abortion has become a common method of limiting and spacing birth, but it should on no account to be promoted as family planning method. ${ }^{3}$ Unwanted pregnancies in youth and complications of induced abortions are an important health problem in the world (WHO, 2011). Unwanted pregnancies place a woman at additional risk, if she seeks abortion and safe services are not available. ${ }^{4}$ About 42 million of induced abortion performed each year, of which 20 million of the total abortions are thought to be unsafe, nearly $98 \%$ of these unsafe abortions are done in developing countries. Due to abortion related complications, about 47,000 women die annually in these developing countries and a further 5 million women suffer disabilities, about $13 \%$ of all maternal deaths worldwide, or approximately 200 deaths per day are due to unsafe abortions. ${ }^{5}$

The first national study of the incidence of abortion and unintended pregnancies in India showed estimated 15.6 million abortion were performed in India in 2015 and abortion rate was $47 / 1000$ women in $15-49$ age group. $80 \%$ were achieved by medical abortion pill, $14 \%$ surgically in health facilities, and 5\% outside health facilities using other typically unsafe methods. It also showed estimated unintended pregnancy rate was $70 / 1000$ women among $15-49$ age group in 2015.6 In present times with the entire focus of women's health being on her reproduction, abortion practice has become a critical issue despite constant efforts by Government, unmet needs still remain.

\section{METHODS}

It is a prospective analytic study conducted in department of Obstetrics and Gynaecology, at Agartala Government Medical College for 3 years ( $1^{\text {st }}$ January 2015 to $31^{\text {st }}$ December 2017, among which 2.5 years for sample collection and 6 months for analysis of the sample).

All patients of reproductive age group (15-45 years), irrespective of their marital status with the complications related to medical abortion have been included in this study.

\section{Inclusion criteria}

- All women of reproductive age group irrespective of their marital status who attended OPD or labour room or referred from other hospital or shifted from other department with the complications of medical abortion.

\section{Exclusion criteria}

- The women who did not give consent were excluded from the study.

Agartala Govt. Medical College is a tertiary referral institution that provides twenty-four-hour emergency obstetric services. All reproductive age group women (15-45 years age) hospitalized with the complications following medical abortion in department of Obstetrics and Gnaecology were enrolled. Patient demographic profile including age, age at marriage, education, socio economical status, obstetric profile with number of previous living child, age of last child, number and methods of previous abortion, KAP of contraception with reasons for discontinuation of contraception, gestational age and reasons for current abortion were analysed. Accessibility of abortion pill, outcome of medical abortion was assessed. Finally, each patient was managed according to departmental protocol.

\section{Statistical analysis}

Data collected were presented in frequency and percentage and data analysis has been done in Epi info version 7.0.

\section{RESULTS}

\section{Socio demographic profile}

The socio demographic profile of total 100 study population suggest majority of women (37\%) were in between 18-25 years age group (Figure 1). 45\% women had marriage at early age between 15 to 20 years, followed by $37 \%$ in between $21-25$ and $2 \%$ women had marriage bellow 15 years (Figure 1). One unmarried student admitted after self-induced abortion. Majority of women (56\%) belong to Bengali community, followed by $26 \%$ of indigenous group, $18 \%$ Muslim (Table 1).

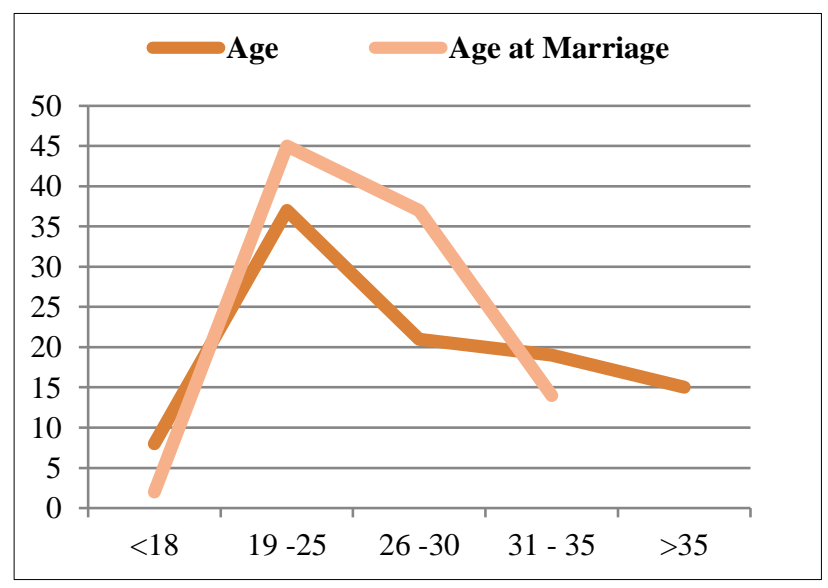

Figure 1: Distribution of age and age of marriage. 


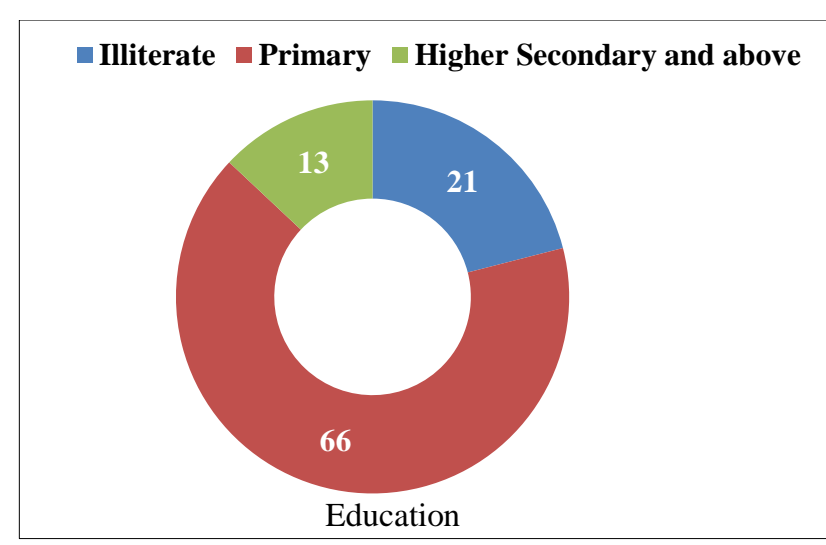

Figure 2: Distribution of educational status.

Table 1: Socio-demographic profile.

\begin{tabular}{|ll|l|}
\hline \multirow{4}{*}{$\begin{array}{l}\text { Socioeconomic } \\
\text { status }\end{array}$} & Parameters & Numbers \\
\cline { 2 - 3 } & Upper middle & 05 \\
\cline { 2 - 3 } & Middle & 25 \\
\cline { 2 - 3 } Community & Lower middle & 46 \\
\cline { 2 - 3 } & Lower & 24 \\
\hline \multirow{4}{*}{ Residence } & Muslims & 56 \\
\cline { 2 - 3 } & Others & 18 \\
\hline \multirow{5}{*}{$\begin{array}{l}\text { Profession of } \\
\text { the spouse }\end{array}$} & Urban & 26 \\
\cline { 2 - 3 } & Urban slum & 17 \\
\cline { 2 - 3 } & Rural & 33 \\
\cline { 2 - 3 } & Self employed & 04 \\
\cline { 2 - 3 } & Private job & 33 \\
\hline
\end{tabular}

A total $66 \%$ women had educated up to primary school followed by illiterate (21\%) (Figure 2). 50\% women were from rural area. $46 \%$ women belong to lower middle class. $98 \%$ of women were home maker and their spouse mostly were agriculture worker (47\%) (Table 1).

\section{Obstetric profile}

Most women who had taken medical abortion were with single living child (41\%), $10 \%$ were nulli parous and $59 \%$ of them had their last child birth within 1 year (Table 2). Interestingly, 7\% women had child less than 6 months and $5 \%$ cases youngest child age was more than 10 years. Nearly two third of the women had taken abortifacient for the first time, whereas $2 \%$ women had medial abortions three or more times in past.

\section{KAP of contraception}

More than $4 / 5^{\text {th }}$ women $(88 \%)$ had idea about one or more varieties of contraception, but $12 \%$ were ignorant of it. Surprisingly only $14 \%$ of women had idea about emergency contraception. 20\% women knew about natural methods but only $13 \%$ used them on regular and on off basis, in case of oral pills it was $40 \%$ and $22 \% .3 \%$ conceived in postpartum period after spontaneous expulsion of PPIUCD (Table 3). The common reasons for contraception discontinuation were noted to be due to intolerable side effects of oral pills $(23 \%), 11 \%$ due to forgetfulness/missed pills and $10 \%$ were due to nonavailability at government outlets. Numerous other reasons were also cited by the women such as fear of future fertility, not sure of effectiveness, unwillingness of spouse etc.

Table 2: Obstetric profile.

\begin{tabular}{|c|c|c|}
\hline Obstetric profile & Parameters & Numbers \\
\hline \multirow{4}{*}{ Previous living child } & 0 & 10 \\
\hline & 1 & 41 \\
\hline & 2 & 33 \\
\hline & 3 and more & 16 \\
\hline \multirow{4}{*}{$\begin{array}{l}\text { Previous abortions } \\
\text { (both medical and } \\
\text { surgical) }\end{array}$} & 0 & 74 \\
\hline & 1 & 20 \\
\hline & 2 & 04 \\
\hline & 3 or more & 02 \\
\hline \multirow{5}{*}{ Age of last child } & $<6$ months & 07 \\
\hline & 6-12 months & 52 \\
\hline & $1-5$ years & 17 \\
\hline & $\begin{array}{l}\text { More than } 5 \\
\text { years }\end{array}$ & 14 \\
\hline & $\begin{array}{l}\text { Total number } \\
\text { of cases }\end{array}$ & 100 \\
\hline
\end{tabular}

Table 3: KAP in use of contraception.

\begin{tabular}{|c|c|c|}
\hline & Parameters & Number \\
\hline \multirow{2}{*}{$\begin{array}{l}\text { Knowledge of } \\
\text { contraception }\end{array}$} & Yes & 88 \\
\hline & No & 12 \\
\hline \multirow{5}{*}{$\begin{array}{l}\text { Knowledge } \\
\text { about various } \\
\text { methods of } \\
\text { contraception }\end{array}$} & OCP & 40 \\
\hline & IUCD & 12 \\
\hline & Barrier & 30 \\
\hline & Emergency & 14 \\
\hline & Natural & 20 \\
\hline \multirow{5}{*}{$\begin{array}{l}\text { Use of various } \\
\text { contraception }\end{array}$} & $\mathrm{OCP}$ & 22 \\
\hline & IUCD & 05 \\
\hline & Barrier & 16 \\
\hline & Emergency & 2 \\
\hline & Natural & 13 \\
\hline \multirow{7}{*}{$\begin{array}{l}\text { Reasons for } \\
\text { discontinuation } \\
\text { of contraception }\end{array}$} & Intolerable side effects & 23 \\
\hline & Missed pill & 11 \\
\hline & Non availability & 10 \\
\hline & Husband disagree & 04 \\
\hline & $\begin{array}{l}\text { May cause problem in } \\
\text { future fertility }\end{array}$ & 07 \\
\hline & Not sure of effectiveness & 05 \\
\hline & No reply & 08 \\
\hline \multirow{4}{*}{$\begin{array}{l}\text { Duration of } \\
\text { discontinuation }\end{array}$} & Never used & 57 \\
\hline & $<6$ months & 24 \\
\hline & 6-12 months & 09 \\
\hline & $>12$ months & 10 \\
\hline
\end{tabular}




\section{Reasons for termination of pregnancy}

Unplanned pregnancy (49\%), last child too young (17\%) and family complete $(16 \%)$ were the most common reasons for termination of pregnancy (Table 4). Termination of pregnancy was attempted at $<8$ weeks $(52 \%)$, at 9 to 12 weeks $(41 \%)$ and at $\geq 12$ weeks $(7 \%)$. In only $5 \%$ cases abortion pills were prescribed by qualified personal, rest of the case abortion pills were procured over the counter (Table 4 ).

Table 4: Accessibility of abortion pill, gestational age of termination, reasons for termination of pregnancy.

\begin{tabular}{|c|c|c|}
\hline & Parameters & Number \\
\hline \multirow{7}{*}{$\begin{array}{l}\text { Reasons for } \\
\text { abortion }\end{array}$} & Unplanned pregnancy & 49 \\
\hline & Too young last child & 17 \\
\hline & Family complete & 16 \\
\hline & Medical ground & 02 \\
\hline & Yet to complete study & 04 \\
\hline & No reply & 11 \\
\hline & unmarried & 01 \\
\hline \multirow{3}{*}{$\begin{array}{l}\text { Gestational } \\
\text { age }\end{array}$} & $<8$ weeks & 52 \\
\hline & 8-12 weeks & 41 \\
\hline & $>12$ weeks & 07 \\
\hline \multirow{4}{*}{$\begin{array}{l}\text { Abortion pill } \\
\text { procured }\end{array}$} & Over the counter & 38 \\
\hline & By husband & 42 \\
\hline & Qualified professionals & 05 \\
\hline & Relatives and friends & 15 \\
\hline
\end{tabular}

\section{Management}

\section{Investigation}

Table 5 shows important investigations that carried out to plan the management of each case. Ultrasonography examination had revealed incomplete abortion $(60 \%)$, complete abortion (23\%), 6 cases had viable first trimester pregnancy, 6 cases diagnosed as case of ruptured ectopic pregnancy, one case as hydatidiform mole. Major complication following abortion was anaemia (45\%) and sepsis $(33 \%)$.

Table 5: Investigations of study population.

\begin{tabular}{|lll|}
\hline \multirow{4}{*}{ Investigations } & Parameters & Number \\
\hline \multirow{4}{*}{ USG } & Incomplete abortion & 60 \\
\cline { 2 - 3 } & Complete abortion & 23 \\
\cline { 2 - 3 } & Trophoblastic disease & 01 \\
\cline { 2 - 3 } Anaemia & Viable pregnancy & 10 \\
\cline { 2 - 3 } & Ectopic pregnancy & 06 \\
\hline \multirow{4}{*}{$\begin{array}{l}\text { Evidence of } \\
\text { sepsis }\end{array}$} & 7-9 gm\% & 45 \\
\cline { 2 - 3 } & $>10$ gm\% & 38 \\
\cline { 2 - 3 } & No sepsis & 17 \\
\cline { 2 - 3 } & Grade I sepsis & 67 \\
\cline { 2 - 3 } & Grade II sepsis & 08 \\
\hline
\end{tabular}

\section{Treatment}

Surgical evacuation was done for all incomplete abortions $(70 \%)$ and hydatidiform mole under antibiotic coverage (Table 6). Emergency laparotomy was done all cases for ruptured ectopic pregnancy. All 6 cases with viable pregnancy counselled to continue pregnancy. $58 \%$ of the patients required blood transfusion for anaemia. Anaemia was also corrected with iron infusion according to department protocol. Most of the patient (78\%) was discharged from hospital within 72 hours.

Table 6: Different treatments modalities that offered.

\begin{tabular}{|lll|}
\hline Treatment & Parameters & Number \\
\hline \multirow{4}{*}{ Modalities } & Suction and evacuation & 71 \\
\cline { 2 - 3 } & Conservative/medical & 16 \\
\cline { 2 - 3 } & Dilatation and evacuation & 01 \\
\cline { 2 - 3 } & Laparotomy & 06 \\
\cline { 2 - 3 } & Continuation of pregnancy & 06 \\
\hline \multirow{2}{*}{$\begin{array}{l}\text { Blood } \\
\text { transfusion }\end{array}$} & $\leq 2$ units & 50 \\
\cline { 2 - 3 } & $\leq 3$ to 4 units & 07 \\
\cline { 2 - 3 } $\begin{array}{l}\text { Iron } \\
\text { infusion }\end{array}$ & FFP & 02 \\
\hline \multirow{2}{*}{$\begin{array}{l}\text { Hospital } \\
\text { stay }\end{array}$} & 600 to $400 \mathrm{mg}$ & 16 \\
\cline { 2 - 3 } & $<3$ days $800 \mathrm{mg}$ & 05 \\
\cline { 2 - 3 } & $\mathbf{4}$-7 days & 78 \\
\hline
\end{tabular}

\section{Post abortion counselling for contraception}

Oral pills were the most common $(31 \%)$ contraception accepted at discharge, followed by concurrent IUCD $(22 \%)$. Permanent sterilization was done in $15 \%$ cases followed by $7 \%$ women agreed for barrier methods. Even after repeated counselling $16 \%$ women did not accept any form of contraception (Table 7). All cases were advised for regular follow-up.

Table 7: Acceptance of contraception in study population.

\begin{tabular}{|ll|}
\hline Contraception & Number \\
\hline Permanent sterilization & 15 \\
\hline OCP & 31 \\
\hline IUCD & 22 \\
\hline Barrier & 07 \\
\hline None & 16 \\
\hline
\end{tabular}

All the patients realized their sufferings and promise not to repeat same mistake.

\section{DISCUSSION}

\section{Socio-demography}

In this study, 58\% women were in 18-30 age group, which is similar to Kumari R et al, Guleria et al, Bahadur 
et al. ${ }^{7-9}$ Authors found 40\% women between 25-35 years, which is lower than Singh et al (70\% in 26-35 years). ${ }^{10}$ To be very surprise, $8 \%$ patients were below 18 years, which is higher than Harshini $\mathrm{V}$ et al $(4.7 \%$ in under 18 years). ${ }^{11}$ Singh et al (5\% adolescent), Srivastava et al also found higher rate of medical abortion in adolescent group. ${ }^{10,12}$ Younger age women are more at risk to suffer from post abortion complications.

This study suggests that $87 \%$ of the women were literate up to primary education similar to Gupta et al. ${ }^{13}$ Authors found $21 \%$ were illiterate which is comparable to Reeta et al $(22 \%)$ but lower than Kumari R et al $(50 \%)$, Srivastava et al (46.6\%), but higher than Singh et al $(8 \%))^{7,10,12,14} 1 \%$ women was unmarried among this study patients which is lower than Kumari R et al $(5 \%){ }^{7}$

Nearly $3 / 4^{\text {th }}(70 \%)$ patients in this study were from lower middle class, similar to Kumari R et al ( $65 \%$ ), Gupta et al $(73.68 \%)$, but lower than Singh et al $(60 \%)$ and Reeta et al. ${ }^{7,10,13,14}$ Harshini et al in their study showed all were from low socio economic group. ${ }^{11}$ Authors had more than $4 / 5^{\text {th }}$ patients $(83 \%)$ from urban slum and rural area, higher than Gupta et al $(70.39 \%){ }^{13}$

A total $49 \%$ of the patients were multi parous in this study, which is much lower than Gupta et al $(84.21 \%)$ and $41 \%$ women with 1 living child, much higher than Gupta et al $(14.47 \%) .^{13}$

A total $10 \%$ women were nulli parous in this study, comparable to Harshini et al, $(9.5 \%)$, but lower than Gupta et al $(13.2 \%){ }^{11,13}$

Nearly $3 / 4^{\text {th }}$ women $(74 \%)$ taken medical abortion for the first time, a little lower than Gupta et al $(87.50 \%)$, but much higher than Reeti M et al (22\%). ${ }^{13,15} 20 \%$ women had past history of single abortion, higher than Reeti M (10\%) and $26 \%$ women had past history of two or more abortion, which is higher than Gupta et al (12.50\%). ${ }^{13,15}$

It indicates lack of contraception acceptance even after abortion in this study set up.

\section{KAP of contraception}

A big difference is found between knowledge and use of contraception in this study ( $88 \%$ versus $58 \%$ ), similar to Ghike $\mathrm{S}$ et al $(67.5 \%$ versus $35.7 \%)$ Singh et al. ${ }^{10,16}$ Sunita TH observed that all women knew at least one method of contraception and $48 \%$ used some sort of it. ${ }^{17}$ In this study, $12 \%$ women had no knowledge of contraception, lower than Singh et al (22\%), Srivastava et al $(17.8 \%)$ and Kumari R et al $(42.5 \%) .{ }^{7,10,12}$

It represents failure of contraception awareness programs to reach to the common people. Authors found most women have knowledge of oral pills (40\%) followed by barrier $(30 \%)$ and natural method $(20 \%)$, whereas knowledge of pills most common followed by IUCD and barrier method found in Singh et al and Reeta et al. ${ }^{10,14}$ Kumari R et al, showed $37.5 \%$ and $16 \%$ women had idea of barrier method and IUCD respectively, in this study it was $30 \%$ and $12 \% .^{7}$ Mittal S et al found $39.08 \%$ women did not use any contraception where as in this study it was $42 \%$. $^{18}$

In this study authors found most common used method is oral pills $(22 \%)$ followed by barrier $(16 \%)$ and natural methods $(13 \%)$, similar to Singh et al. ${ }^{10}$

Knowledge of EC pill was present in $24 \%$ women in this study, much higher than Reeti $\mathrm{M}$ et al (1\%), Mittal S et al (1.4\%), Gupta et al (5.26\%), Manila Kushal et al (14.3\%). ${ }^{13,15,18,19}$ Authors found very few women (2\%) used EC pill, but none have used it in study of Mittal S et al. ${ }^{18}$

In this study authors found that most common cause of discontinuation of pregnancy was unable to tolerate side effects (23\%), followed by missed pill (11\%), nonavailability of contraception (10\%), husband refusal (4\%). Ghike $\mathrm{S}$ et al found main reason for non-practice of contraception was family pressure $(59 \%) .{ }^{16}$ Sunita T et al showed Reasons for not using contraception were desire to have child (25\%), desire for boys $(13.4 \%)$, worried of side effects $(16.3 \%)$, opposition from family members $(11.5 \%)$, felt pregnancy was naturally spaced $(11.5 \%)$, could not avail contraceptive facilities (5.7\%), inconvenient to use (5.7\%). ${ }^{17}$ Side effects and nonavailability of contraception along with family pressure has definite role in consistent use of oral pills.

\section{Present abortion profile}

Authors found most common reason for abortion was unplanned pregnancy (49\%), followed by last child too young (17\%) and family complete (16\%). 11\% women were not able to give any reply and $4 \%$ women told they want to continue study.

Khokhar and Gulati in their study noted that most common reasons for abortion were unplanned pregnancy $(62.50 \%)$, Inadequate income $(52.08 \%)$, family complete $(31.25 \%)$, contraceptive failure $(10.41 \%)$, female fetus $(2.08 \%)$, health problem $(2.08 \%) .{ }^{20}$ Dhilon et al, found most common reason for abortion were they did not want any more children (42\%), last child too young $(23.4 \%){ }^{21}$

Gupta et al showed $63.16 \%$ women have undergone MTP for family size completed, $20.40 \%$ for previous baby too young, and $29.61 \%$ women had no reply. ${ }^{13}$ This study result regarding causes of abortion is compatible with other studies done all over India.

Authors found that abortion pills were procured from chemist shop (in $38 \%$ cases); in $5 \%$ of the case the abortion pills were prescribed by qualified professionals. Harshini et al showed $57.14 \%$ cases medicine prescribed 
by qualified medical personal and $42.85 \%$ over the counter. ${ }^{11}$

\section{Treatment}

Surgical evacuation was done in $70 \%$ cases in this study, lower than Harshini et al $(85.7 \%)$, but higher than Kumari $\mathrm{R}$ et al $(45 \%))^{7,11}$ Coyaji et al, in their study reported $75 \%$ women had no complication after medical abortion, $14 \%$ had bleeding, $4 \%$ needed frequent visit. ${ }^{22}$

In this study, $58 \%$ of cases required blood transfusion for severe anaemia and $21 \%$ received calculated dose of iron therapy (Iron Sucrose) for mild to moderate anaemia. Harshini et al observed much smaller number of patients who required blood transfusion $(2.38 \%){ }^{11}$

Majority of the studies had shown incomplete abortion with anaemia is the most common complication following inappropriate use of over the counter medical abortion pill. ${ }^{7,11}$

\section{Post-abortion contraception}

In this study, after management of abortion related complications $22 \%$ of them accepted IUCD which is similar to Sunita Mittal et al (18.3\%) and 7\% accepted barrier which is much less than Sunita Mittal et al $(38 \%) .{ }^{18}$ Mukhopadhyay et al found that $35.8 \%$ accepted Copper T, 30\% accepted permanent sterilization after MTP as a mode of contraception. ${ }^{23}$

Gupta et al, showed 34\% accepted IUCD, 64\% permanent sterilization, $2.16 \%$ none as post abortion contraception. ${ }^{13}$

Fact is acceptance of contraception is low even after abortion. Post-abortion contraception and family planning is a major tool towards reduction of abortion related morbidity and mortality for its cost effectiveness in preventing repeat unwanted pregnancy and induced unsafe abortion. In spite, of the availability of safe and effective contraception the need for it has not been met due to the ignorance amongst women especially in rural and tribal areas. ${ }^{1}$

\section{CONCLUSION}

Young adult, multi parous women from lower middleclass family with poor knowledge about contraception seek self-induced medical abortion for unplanned pregnancy. Poor awareness about abortion facilities within the law forced them to adopt faulty measures lead to numerous complications related to abortion which raises hospital admission burden. Easy procurement of abortion pill over the counter creates nuance for clients and service provider. Strict vigilance by the specific authority is important step forward to prevent untoward complications related with self-induced abortions Pregnancy termination should be done by qualified medical personal. Strategies should be implemented with accurate information about how to use medical abortion safely.

More efforts are required to motivate reproductive age women to avoid unwanted pregnancies by using contraceptive measures to avoid undue complications. Target group should be males in addition to females as women are still fighting for their reproductive rights in our society.

Funding: No funding sources Conflict of interest: None declared

Ethical approval: The study was approved by the Institutional Ethics Committee

\section{REFERENCES}

1. Nanda AR. Understanding the un meet needs for contraception and challenges for meeting the same in India: Chatterjee A, Mahapatra PD eds. Obstetrics and Gynaecology, Highlights: an Evidence Based Review, $1^{\text {st }}$ Ed. Kolkata: Modern Graphica; 2006:346-354.

2. Park K. Medical termination of pregnancy act, 1971. In: Park k, eds. Park's Textbook of preventive and social medicine. $18^{\text {th }}$ Ed. Jabalpur: Banarsidas Bhanot; 2005:371-381.

3. Henshaw SK, Singh S, Hass T. The incidence of abortion worldwide. Int Fam Plann Perspect. 1999;25(suppl):530-8.

4. Stubblefield PG, Grimes DA. Septic abortion. N Engl J Med. 1994;331(5):310-4.

5. World Health Organization. Unsafe abortion incidence and mortality: global and regional levels in 2008 and trends during 1990-2008. World Health Organization. 2012. Available at: https://apps.who.int/iris/handle/10665/75173. Accessed on $20^{\text {th }}$ April 2020.

6. International Institute for Population Science (IIPS), Mumbai; Population Council New Delhi; New York based Guttmacher Institute. National estimate of abortion in India released. Available at: https://www.guttmacher.org/news-release/2017. Accessed on $20^{\text {th }}$ April 2020.

7. Kumari R, Shahnawa K, KAP of medical abortion in women-a longitudinal study from Patna, Bihar. J Evid Based Med Health. 2018;5(12):1037-40.

8. Guleria K, Bansal S, Agarwal N, Grover V. Women with septic abortion: Who, how and why? A prospective study from tertiary care hospital in India. Indian J Public Health. 2006;50(2):95-6.

9. Bahadur A, Mittal S, Sharma JB, Sehgal R. Socio demographic profile of women undergoing abortion in tertiary centre. Arch Gynecol Obstet. 2008;278(4):329-32.

10. Singh CPK, Sarkar R. Knowledge of contraception among Indigenous peoples of Manipur coming for abortion in a tertiary hospital. J Dent Med Sci. 2016;15(10):27-9. 
11. Nataraj HG, Harshini V. Contraceptive knowledge, attitude and practice among women who were seeking for termination of pregnancy. Asian J Biomed Pharma Sci. 2013;3(23):4-6.

12. Srivastava R, Srivastava DK, Jina R, Srivastava K, Sharma N, Sana S. Contraceptive knowledge, attitude and practice (KAP Survey). J Obstet Gynecol India. 2005;55(6):546.

13. Gupta S, Dave V, Sochaliya K, Yadav S. A Study on socio-demographic and obstetric profile of MTP seekers at Guru Govind Singh Hospital, Jamnagar. Age. 2012;15(20):20-5.

14. Bansiwal R, Singh P, Bajpai S. Practice of contraception in this modern world: still a myth? Int J Reprod Contracept Obstet Gynaecol. 2015;4(3):674-7.

15. Mehra R, Goel P, Dua D, Huria A. Knowledge of emergency contraception among women coming for induced abortion. J Obstet Gynaecol India. 2006;56(3):233-5.

16. Ghike S, Joshi S, Bhalerao A, Kawthalkar A. Awareness and contraception practices among woman -an Indian rural experience. South Asian Federat Obstet Gynaecol. 2010;2(1):19-21.

17. Sunita TH, Desai RM. Knowledge, Attitude and Practice of contraception among women attending a tertiary care hospital in India. Int. J Reprod Contracept Obstet Gynecol; 2013;2(2):172-6.

18. Mittal S, Bahadur A, Sharma JB. Survey of the attitude to, knowledge and practice of contraception and medical abortion in women attending a family planning clinic. J Turkish German Gynaecol Assoc. 2008;9(1):29-34.

19. Kushal M, Maru L, Dare A. Emergency contraceptive knowledge, attitude and practice in women presenting to family planning out patient clinic in central India. J South Asian Federat Obstet Gynaecol. 2014;6(1):21-4.

20. Khokar A, Gulati N. Profile of induced abortions in women from an urban slum of Delhi. Indian J Comm Med. 2000;25(4):10-2.

21. Dhilon BS, Chandhiok N, Kambo I, Saxena NC. Induced abortion and concurrent adoption of contraception in the rural areas of India (an ICMR task force study). Indian $\mathrm{J}$ Med Sci. 2004;58(11):478-84.

22. Coyaji K. Early medical abortion in India: three studies and their implication for abortion services. J Am Med Womens Assoc. 2000; 55(3 suppl):191-4.

23. Mukhopadhyay AK, Ghosh A, Goswami S, Adhikari S. Fertility regulation 5-year study. J Obstet Gynaecol of India. 2008;58(5):421-4.

Cite this article as: Pal A, Baidya JL. Knowledge, attitude and practice of contraception complications among hospitalized women following self-induced medical abortion at tertiary hospital. Int J Reprod Contracept Obstet Gynecol 2020;9:2840-6. 